NOTICE: this is the author's version of a work that was accepted for publication in Evolution and Human Behavior. Changes resulting from the publishing process, such as peer review, editing, corrections, structural formatting, and other quality control mechanisms may not be reflected in this document. Changes may have been made to this work since it was submitted for publication. A definitive version was subsequently published in Evolution and Human Behavior, [Vol. 31, Issue 1, (2011)]

DOI: http://dx.doi.org/10.1016/i.evolhumbehav.2010.09.001 


\title{
Like father, like self: emotional closeness to father predicts women's preferences for self-resemblance in opposite-sex faces
}

\author{
Christopher D. Watkins, Lisa M. DeBruine, Finlay G. Smith, \\ Benedict C. Jones, Jovana Vukovic \& Paul Fraccaro \\ School of Psychology, University of Aberdeen, Aberdeen, UK.
}

\begin{abstract}
Kin recognition is an essential component of kin-directed adaptive behavior. Consequently, potential mechanisms of kin recognition, such as learning a kin phenotype from family members (familial imprinting) or self (self-referential phenotype matching), have been the focus of much research. Studies using computer-manipulated self-resemblance show effects for both same-sex and opposite-sex faces and have been interpreted as evidence for self-referential phenotype matching. However, more recent research on sex-contingent face processing suggests that visual experience with faces of one sex has little influence on perceptions of faces of the other sex, calling into question how self-referential phenotype matching can influence perceptions of opposite-sex faces. Because children resemble their parents, familial imprinting could influence preferences for self-resemblance, reconciling these seemingly incompatible results for sex-contingent face processing and effects of self-resemblance on perceptions of opposite-sex faces. Here we show that women's reported emotional closeness to their father, but not mother, is positively correlated with their preferences for self-resemblance in opposite-sex, but not same-sex, individuals. These findings implicate familial imprinting in preferences for self-resemblance in opposite-sex individuals and raise the possibility that familial imprinting and self-referential phenotype matching have context-specific effects on attitudes to self-resembling individuals.
\end{abstract}

KEY WORDS: kin recognition; self-resemblance; faces; familial imprinting; phenotype matching; sex- contingent face processing; inclusive fitness; optimal outbreeding

Kin recognition is essential to gain the fitness benefits of directing investment and altruistic behaviour towards close genetic relatives (i.e., inclusive fitness theory; Hamilton, 1964) and to balance the costs of inbreeding on off spring health against the potential costs of mating with someone who is too distantly related (i.e., optimal outbreeding theory; Bateson, 1982). Phenotype matching refers to the use of the sensory modalities (e.g., vision, audition, and olfaction) to recognize kin via a mental kin template against which individuals are compared (e.g., Mateo, 2004). Such a kin template may be learned from observing one's own phenotype (self-referential phenotype matching, e.g., Mateo \& Johnston, 2003) or the phenotype of others who are likely to be closely related (familial imprinting, e.g., Kendrick, Hinton \& Atkins, 1998). Self-referential phenotype matching is thought to be the least corruptible method because only selfreferential phenotype matching can, for example, distinguish full siblings from maternal half siblings (Hauber \& Sherman, 2001). However, familial imprinting may be easier and the opportunity to do so may be very reliable (Hauber \& Sherman, 2001). Consequently, there is debate about the extent to which familial and self-referential phenotype matching contribute to kin recognition in a given species (Hauber \& Sherman, 2001; Mateo \& Johnston, 2003).

Evidence for self-referential phenotype matching in humans comes from studies of preferences for computergenerated self-resembling faces (Bressan \& Zucchi, 2009; see also DeBruine, Jones, Little \& Perrett, 2008 for a review). Self-resemblance enhances perceptions of attractive- ness in opposite-sex faces (Saxton et al., 2009), although to a much smaller degree than in same-sex faces (DeBruine, 2004). Self-resemblance in same-sex faces enhances co-operation in economic games (DeBruine, 2002; Krupp, DeBruine \& Barclay, 2008) and has a smaller effect on perceptions of attractiveness than on perceptions of trustworthiness in opposite-sex faces (DeBruine, 2005). These findings demonstrate that self-resemblance has effects on perceptions of faces that are consistent with predictions from both inclusive fitness theory (Hamilton, 1964) and optimal outbreeding theory (Bateson, 1982).

Evidence for familial imprinting in humans comes from studies of preferences for parental traits. For example, romantic partners and opposite-sex parents tend to be similar in measured facial proportions (Bereczkei, Hegedus \& Hajnal, 2009), eye colour (Little et al., 2003), ethnicity (Jedlicka, 1980), age (Perrett et al., 2002) and general facial appearance (Bereczkei, Gyuris \& Weisfeld, 2004). Additionally, the extent to which romantic partners or preferred faces resemble opposite-sex parents is positively correlated with their reported emotional closeness to the opposite-sex parent (Bereczkei et al., 2002, 2004; Wiszewska, Pawlowski \& Boothroyd, 2007). These findings are consistent with a large body of literature on non-human animal imprinting (see Mateo, 2004 for a review) and implicate familial imprinting in human mate preferences.

As noted above, previous research on self-resemblance has tended to emphasize the possible effects of selfreferential phenotype matching (Bressan \& Zucchi, 2009; 

DeBruine et al., 2008). However, research on sex-contingent face processing has demonstrated that visual experience with faces of one sex increases preferences for same-sex faces with similar features, but has reduced or no effect on preferences for opposite-sex faces (Bestelmeyer et al., 2008, 2010; Jaquet \& Rhodes, 2008; Little, DeBruine \& Jones, 2005). Such research raises the question of how self-referential phenotype matching could influence the perception of oppositesex faces. If visual experience with self can only influence perceptions of same-sex faces, a mechanism other than self-referential phenotype matching may influence preferences for self-resemblance in opposite-sex faces. Reconciling these seemingly incompatible findings for sex-contingent face processing and effects of self-resemblance on perceptions of opposite-sex faces is essential for a full understanding of the proximate mechanisms that support kin-directed adaptive behavior.

Because parents and offspring resemble each other (Bredart \& French 1999; Bressan \& Dal Martello, 2002; Bressan \& Grassi, 2004; Nesse et al., 1990; Oda et al., 2005), effects of self-resemblance may actually reflect attitudes towards parental traits. Because the effects of familial imprinting are modulated by women's emotional closeness to their father (Bereczkei et al., 2004; Wiszewska et al., 2007), a relationship between emotional closeness to father and women's preferences for self-resembling faces would implicate familial imprinting as a mechanism for the effects of self-resemblance in opposite-sex faces.

In light of the above, we investigated the relationship between women's reported emotional closeness to their fathers or mothers and their preferences for self-resembling male and female faces. Since previous research has shown that effects of parental resemblance in a mate-choice context are specific to the opposite-sex parent (e.g., Jedlicka, 1980; Little et al., 2003), we predicted that women's emotional closeness to father, but not mother, would be positively correlated with preferences for self-resemblance. Because research on face perception suggests that visual experience with faces of one sex influences perceptions of other faces of that same sex more than faces of the opposite sex (Bestelmeyer et al., 2008, 2010; Jaquet \& Rhodes, 2008; Little, DeBruine \& Jones, 2005), one would expect women's emotional closeness to their fathers to predict their preferences for self-resemblance in male faces, but not necessarily in female faces. While other research has demonstrated a positive relationship between women's closeness to their father during childhood and the extent to which women demonstrate a preference for male faces that resemble their father (Bereczkei et al., 2004; Wiszewska, Pawlowski \& Boothroyd, 2007), here we aim to investigate the extent to which a similar relationship occurs for preferences for faces that resemble self.

\section{Methods}

\section{Participants}

Participants were 108 heterosexual female undergraduates at the University of Aberdeen (Mean age $=20.0$ years,
$S D=2.8$ years). Each participant was paired with a control participant from the same sample who was matched for phenotypic category (African, European or West Asian) and age (mean absolute age difference between controls and participants $=0.35$ years, $S D=0.58$ years ).

\section{Transformed facial stimuli}

Facial resemblance was manipulated following methods used in previous studies (DeBruine, 2004, 2005). Briefly, participants' photographs were taken two weeks before the experiment as part of a series of unrelated tests into face and voice preferences (to minimize the chance that participants would guess the nature of the experiment). Each participant's image (Figure 1a) was used to transform a composite female (Figure 1b) and a composite male face (Figure 1d). Transforms were made by calculating the shape difference between the participant's face and a composite face of the same sex and ethnic category (Figure $1 \mathrm{~b}$ ). To make same-sex transforms (Figure 1c), 50\% of this difference was applied to the same-sex composite face. For opposite-sex transforms (Figure 1e), $50 \%$ of this difference was applied to the oppositesex composite face. Hair, clothing and background were removed from the final images. Importantly, this method of transformation does not cause opposite-sex self-resembling faces to appear androgynous (see DeBruine et al., 2008 for a detailed discussion). Preference for self-resemblance was measured by comparing these self-resembling faces to otherresembling faces, which were made using the same methods for ten male and ten female individual faces that were unknown to the participants.

\section{Procedure}

Following previous studies of preferences for selfresemblance (DeBruine, 2004, 2005), participants viewed pairs of faces in which one face was self-resembling and the other face was other-resembling. Participants viewed pairs on a computer screen and indicated which face they found more attractive by clicking on the face. Faces were presented in two randomly ordered blocks: one with male faces and one with female faces. In each block, 20 face pairs were presented. Ten of these face pairs consisted of the participant's self-resembling face and one of the ten otherresembling faces. The other ten face pairs consisted of the control's self-resembling face and the ten other-resembling faces. The order of presentation of face pairs was randomised for each block and the side of presentation of self- and otherresembling faces was randomised for each trial.

\section{Parental support questions}

During the test session, women were asked "How much emotional support did you receive from your male parent during your childhood?" Participants rated this on a scale of 1 to 7 ( $1=$ no support, $7=$ a lot of support $)$. Women were also asked an equivalent question about their female parent. One participant did not provide a rating for her mother and was excluded from corresponding analyses. Previous research 

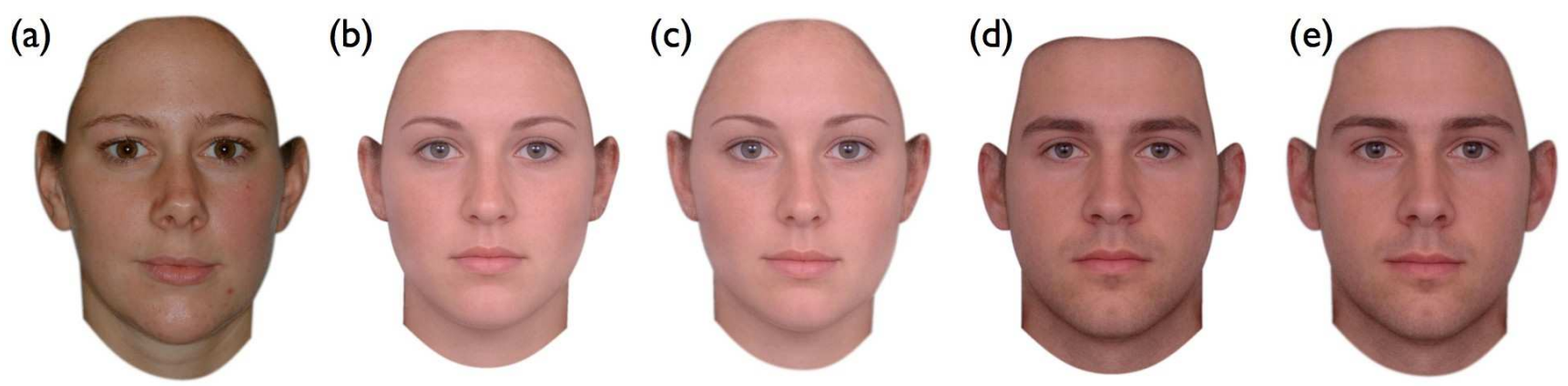

Figure 1. An individual face (a), an average female face (b), a self-resembling female face (c), an average male face (d), and a selfresembling male face (e).

(e.g., Hall, 2009) shows that multi-item questionnaires of perceived parental support show extremely high correlations among items (see also our pilot study below), suggesting that a single-item questionnaire is sufficient to capture perceived parental support. The order in which participants completed this questionnaire and the face preference test was randomized across participants. The mean rating for emotional closeness to father was $4.56(S D=1.96)$ and for mother was $6.39(S D=1.16)$.

\section{Pilot Study}

In a pilot study, we investigated the extent to which our single-item measure of emotional closeness to mother or father during childhood reflects the same construct as other, previously used questionnaires of parental relationships. Fifty women (mean age $=23.7$ years, $S D=5.3$ years) who were raised by their biological parents participated in an online test in which they completed four different questionnaires separately for judgments of mother and father. None of the women who participated in this pilot study took part in the main study. The four questionnaires were the emotional warmth subscale of the short-form EMBU (EMBUe: Arrindell et al., 1999), the care subscale of the Parental Bonding Instrument (PBIc: Parker, Tupling \& Brown, 1979), the Parental Positivity Scale (PPS: Wiszewska et al., 2007), and our own single-item question. We used principal components analysis to determine if the four questionnaires measured the same construct; if each questionnaire has a high and relatively equal loading on a single factor, this would suggest that each of the questionnaires is an equally valid measure of parental closeness. For relationship with mother, this principal components analysis produced a single factor that explained $80 \%$ of the variance in scores, with each of the individual scores having factor loadings of .90 (EMBUe), .93 (PBIc), .83 (PPS), and .91 (our single item). A corresponding analysis of scores for attitudes to father also produced a single factor that explained $74 \%$ of the variance in scores, with each of the individual scores having factor loadings of .86 (EMBUe), .90 (PBIc), .81 (PPS), and .86 (our single item).

\section{Initial processing of data}

First, four scores were computed for each participant, reflecting the number of times out of ten that the same-sex selfresembling, same-sex control-resembling, opposite-sex selfresembling, or opposite-sex control-resembling images were chosen as more attractive than the other-resembling images. These scores could range from zero (the self- or controlresembling image was never chosen as the more attractive of the pair) to ten (the self- or control-resembling image was chosen as the more attractive in all ten pairings). The same four scores were also computed for each participant's matched control.

Each participant's preference for same-sex selfresemblance was calculated as own score for same-sex self-resembling faces minus their control participant's score for these same faces (i.e., the control participant's control-resembling score). Preferences for opposite-sex self-resemblance were calculated in the same way. For example, if participants A and B were matched controls, A's preference for self-resemblance would be calculated as A's preference for A-resembling faces minus B's preference for A-resembling faces. Likewise, B's preference for selfresemblance would be calculated as B's preference for Bresembling faces minus A's preference for B-resembling faces. Importantly, this method controls for the potential effects of participant attractiveness by comparing participants' preferences for self-resembling faces to a matched control. Our findings, therefore, cannot be explained by a potential association between women's own attractiveness and their emotional closeness to their parents.

If participants judged their own images on the same criteria that others judged those faces, the mean difference score should be zero. Difference scores greater than zero would indicate that self-resemblance positively affects judgements of attractiveness, while difference scores less than zero would indicate that self-resemblance negatively affects judgments of attractiveness. This established method for assessing preferences for self-resemblance controls for individual differences in general attractiveness, since aspects of attractiveness that are not related to self-resemblance should not systemat- 
ically affect the preferences of participants in a different way than their controls (DeBruine 2004, 2005).

\section{Results}

To analyze the effect of emotional closeness to father on preferences for self-resemblance, we used a repeatedmeasures ANCOVA with sex of face (same, opposite) as a within-subjects factor and father's emotional support as a covariate. There was a significant main effect of sex of face $\left(F_{1,106}=6.49, p=.012, \eta_{p}^{2}=.058\right)$. Consistent with DeBruine (2004), women were more attracted to self-resemblance in same-sex faces $(\mathrm{M}=0.50, \mathrm{SD}=2.33)$ than opposite-sex faces $(M=-0.06, S D=3.16)$. One-sample t-tests showed that women tended to prefer self-resemblance in same-sex faces $\left(t_{107}=2.23, p=.028\right)$, but not in opposite-sex faces $\left(t_{107}=-0.18, p=.86\right)$. There was no main effect of father's emotional support $\left(F_{1,106}=1.88, p=.17, \eta_{p}^{2}=\right.$ .017). However, the main effect of sex of face was qualified by a significant interaction with father's emotional support $\left(F_{1,106}=4.36, p=.039, \eta_{p}^{2}=.039\right)$. This interaction reflected that the extent to which preferences for selfresemblance were stronger for same-sex than opposite-sex faces (i.e., the sex of face effect reported above and in DeBruine, 2004) was negatively correlated with father's emotional support $\left(r_{108}=-.20, p=.039\right)$.

We used Pearson correlations to examine the interaction between sex of face and father's emotional support separately for same-sex and opposite-sex faces. We observed no correlation between father's emotional support and preference for self-resemblance in same-sex faces $\left(r_{108}=-.04, p=.69\right)$. However, we observed a significant positive correlation between father's emotional support and preference for selfresemblance in opposite-sex faces $\left(r_{108}=.20, p=.036\right)$. In other words, women who reported higher levels of emotional support from their father during childhood had stronger preferences for self-resemblance in opposite-sex faces, but not same-sex faces.

To analyze the effect of emotional closeness to mother on preferences for self-resemblance, we used a repeatedmeasures ANCOVA with sex of face (same, opposite) as a within-subjects factor and mother's emotional support as a covariate. This analysis revealed no main effect of mother's emotional support $\left(F_{1,105}=0.08, p=.78, \eta_{p}^{2}<.001\right)$ and no interaction between mother's emotional support and sex of face $\left(F_{1,105}=0.75, p=.39, \eta_{p}^{2}=.007\right)$. There was no correlation between mother's emotional support and preference for self-resemblance in same-sex faces $\left(r_{107}=.09, p=.36\right)$ or opposite-sex faces $\left(r_{107}=-.03, p=.76\right)$.

We conducted a final ANCOVA with sex of face (same, opposite) as a within-subjects factor and both father's emotional support and mother's emotional support as covariates. Consistent with the previous analyses, this analysis revealed a significant interaction between sex of face and father's emotional support $\left(F_{1,104}=4.27, p=.041, \eta_{p}^{2}=.039\right)$, but not between sex of face and mother's emotional support $\left(F_{1,104}=1.71, p=.19, \eta_{p}^{2}=.016\right)$. There were no significant main effects (all $F_{1,104}<1.33$, all $p>.25$ ).

\section{Discussion}

We investigated the relationship between women's reported emotional closeness to their parents and their preferences for self-resembling faces in order to determine if familial imprinting contributes to preferences for selfresemblance. Preferences for self-resemblance were greater in same-sex faces than opposite-sex faces, replicating DeBruine (2004). However, further analyses show that women's reported emotional closeness to their father as a child was positively correlated with their preferences for self-resemblance in opposite-sex, but not same-sex faces. By contrast, women's reported emotional closeness to their mother as a child did not predict preferences for selfresemblance in either opposite-sex or same-sex faces. Therefore, our findings reconcile the conflict between previously reported effects of self-resemblance in opposite-sex faces (DeBruine 2004, 2005; Saxton et al., 2009) and research on sex-contingent face processing (Bestelmeyer et al., 2008, 2010; Jaquet \& Rhodes, 2008; Little, DeBruine \& Jones, 2005), suggesting that experience with an opposite-sex parent's face contributes to preferences for self-resemblance in opposite-sex faces.

The relationship that we observed between women's reported emotional closeness to their fathers and their preferences for self-resembling faces complements similar studies which show an association between emotional closeness to a parent and the extent to which partners or preferred faces share similar facial characteristics with the parent (Bereczkei et al., 2002, 2004; Wiszewska et al., 2007). Our findings, however, demonstrate a link between emotional closeness and preferences for self-resemblance, rather than parentresemblance. Additionally, that women's preferences for self-resemblance were related to emotional closeness to father, but not mother, is consistent with previous findings showing preferences for parental traits in opposite-sex individuals that are specific to the opposite-sex parent (e.g., Jedlicka, 1980; Little et al., 2003).

In the current study, the relationship between emotional closeness to father and preferences for self-resemblance in opposite-sex faces appears to be somewhat weaker than the corresponding relationships reported by research that directly tested women's preferences for paternal characteristics (Bereczkei et al., 2004; Wiszewska et al., 2007). This difference in the strength of the relationships is to be expected, however, given that the physical similarity between father and daughter is obviously less than that between father and himself. Note that, although the overall effect of self-resemblance was greater for same-sex than opposite-sex faces (see also DeBruine, 2004), emotional closeness to father was related to judgments of opposite-sex, but not samesex, faces.

While previous studies of preferences for facial selfresemblance emphasized self-referential phenotype matching as a potential mechanism (Bressan \& Zucchi, 2009; DeBruine, 2004, 2005; Platek \& Kemp, 2009; Saxton et al., 2009), the association between emotional closeness to father and women's preferences for self-resemblance in opposite- 
sex faces suggests that familial imprinting contributes to the effects of self-resemblance on attitudes to opposite-sex faces. That women showed preferences for self-resemblance in same-sex faces that were not modulated by emotional closeness to either parent suggests that self-referential phenotype matching contributes to the effects of self-resemblance on attitudes to same-sex faces. Consequently, our findings raise the possibility that familial imprinting and self-referential phenotype matching operate to different extents in different contexts. For example, perceptions of opposite-sex faces may be more influenced by familial imprinting, while perceptions of same-sex faces may be more influenced by selfreferential phenotype matching. Similarly, familial imprinting may be more important in mate-choice contexts, while self-referential phenotype matching may be more important in cooperative contexts.

In the current study, we demonstrate a positive relationship between emotional closeness to father and women's preferences for self-resembling opposite-sex faces that is consistent with corresponding relationships reported in research on women's preferences for paternal traits (Bereczkei et al., 2004; Wiszewska et al., 2007). However, the proximate mechanisms through which emotional closeness to father influences women's preferences are currently unclear. We propose two potential mechanisms that are not mutually exclusive. First, it is likely that emotional closeness to father is strongly correlated with the amount of visual experience daughters had with their father's facial cues during childhood. Since increasing visual experience with an individual face increases attraction to other similar faces (Little, DeBruine \& Jones, 2005), it is possible that the relationship between emotional closeness to father and women's preferences for self-resembling opposite-sex faces is mediated by the amount of visual experience that women had with their father. Second, previous research has shown that the quality (i.e., valence) of women's visual experience with individual faces influences their preferences for other similar faces, such that faces similar to those viewed under pleasant conditions were preferred to faces similar to those seen under unpleasant conditions (Jones et al., 2007). Moreover, this effect of quality' of experience is independent of the effect of quantity' of visual experience (Jones et al., 2007). We suggest that investigating the relative contributions of these two potential mechanisms is an important direction for future research. Additionally, as is the case with virtually all research on parental imprinting, it is unclear whether the ultimate function of imprinting-like effects on mate choice is to achieve an optimal balance between inbreeding and outbreeding or whether it functions simply to generate a template of a desirable member of the opposite-sex (for a review see Irwin \& Price, 1999). For example, if imprinting-like effects were not evident in species where the social father is unlikely to be the genetic father, this would support the first proposal. Similarly, if imprinting-like effects were evident in species where the social father is unlikely to be the genetic father, this would support the latter proposal.

In conclusion, our findings suggest familial imprinting as a novel mechanism contributing to previously reported effects of self-resemblance on perceptions of opposite-sex faces (e.g., DeBruine 2004, 2005; Penton-Voak, Perrett \& Pierce, 1999). Importantly, our findings reconcile these effects with research on sex-contingent face processing, which suggests that visual experience with self (by definition, a same-sex face) has little or no influence on perceptions of opposite-sex faces. Additionally, we have identified women's reported emotional closeness to their father, but not mother, as a source of individual differences in preferences for self-resemblance in opposite-sex, but not same-sex, individuals. This raises the possibility that familial imprinting and self-referential phenotype matching have contextspecific effects on attitudes to self-resembling individuals. We suggest that further tests of this proposal are likely to be a fruitful topic for future study, potentially providing important insights to the adaptive mechanisms through which cues of kinship influence behavior.

\section{References}

Arrindell, W. A., Sanavio, E., Aguilar, G., Sica, C., Hatzichristou, C., Eisemann, M., Recinos, L. A., Gaszner, P., Peter, M., Battagliese, G., Kallai, J. \& van der Ende, J. (1999). The development of a short form of the EMBU: Its appraisal with students in Greece, Guatemala, Hungary and Italy. Personality and Individual Differences, 27, 613-628.

Bateson, P. (1982). Preferences for cousins in Japanese quail. Nature, 295, 236-237.

Bereczkei, T., Gyuris, P., Koves, P., \& Bernth, L. (2002). Homogamy, genetic similarity, and imprinting; parental influence on mate choice preferences. Personality and Individual Differences, 33, 677-690.

Bereczkei, T., Gyuris, P., \& Weisfeld, G. E. (2004). Sexual imprinting in human mate choice. Proceedings of the Royal Society of London B, 271, 1129-1134.

Bereczkei, T., Hegedus, G., \& Hajnal, G. (2009). Facialmetric similarities mediate mate choice: sexual imprinting on opposite-sex parents. Proceedings of the Royal Society of London B: Biological sciences, 276, 91-98.

Bestelmeyer, P. E., Jones, B. C., DeBruine, L. M., Little, A. C., Perrett, D. I., Schneider, A., et al. (2008). Sexcontingent face aftereffects depend on perceptual category rather than structural encoding. Cognition, 107, 353-365.

Bestelmeyer P. E., Jones, B. C., DeBruine, L. M., Little, A. C. \& Welling, L. L. M. (2010). Face aftereffects demonstrate interdependent processing of expressions and the invariant characteristics of sex and race. Visual Cognition, 18, 255-274.

Bredart, S., \& French, R. M. (1999). Do Babies Resemble Their Fathers More Than Their Mothers? A Failure to Replicate Christenfeld and Hill (1995). Evolution and Human Behavior, 20, 129-135.

Bressan, P., \& Dal Martello, M. F. (2002). Talis pater, talis filius: Perceived resemblance and the belief in genetic relatedness. Psychological Science, 13, 213-218.

Bressan, P., \& Grassi, M. (2004). Parental resemblance in one-year-olds and the Gaussian curve. Evolution and Human Behavior, 25, 133-141. 
Bressan, P. \& Zucchi, G. (2009). Human kin recognition is self rather than family-referential. Biology Letters, 5, 336338. DeBruine, L. M. (2002). Facial resemblance enhances trust. Proceedings of the Royal Society of London B, 269, 1307-1312.

DeBruine, L. M. (2004). Facial resemblance increases the attractiveness of same sex more than other sex faces. Proceedings of the Royal Society of London B, 271, 2085-2090.

DeBruine, L. M. (2005). Trustworthy but not lust-worthy: Context-specific effects of facial resemblance. Proceedings of the Royal Society of London B, 272, 919-922.

DeBruine, L. M., Jones, B. C., Little, A. C., \& Perrett, D. I. (2008). Social Perception of Facial Resemblance in Humans. Archives of Sexual Behavior, 37, 64-77.

Hall, S. S. (2009). Paternal influences on daughters' heterosexual relationship socialization: Attachment styles and dispositions toward marriage. Family Science Review, 14, $1-17$.

Hamilton, W. D. (1964). The genetical evolution of social behaviour, International Journal of Theoretical Biology, 7, $1-16$.

Hauber, M. E., \& Sherman, P. W. (2001). Self-referent phenotype matching: theoretical considerations and empirical evidence. Trends in Neurosciences, 24, 609-616.

Irwin, D. E. \& Price, T. (1999). Sexual imprinting, learning and speciation. Heredity, 82, 347-354.

Jaquet, E., \& Rhodes, G. (2008). Face aftereffects indicate dissociable, but not distinct, coding of male and female faces. Journal of Experimental Psychology. Human Perception and Performance, 34, 101-12.

Jedlicka, D. (1980). A test of the psychoanalytic theory of mate selection. Journal of Social Psychology, 112, 295299.

Jones, B. C., DeBruine, L. M., Little, A. C. \& Feinberg, D. R. (2007). The valence of experience with faces influences generalized preferences. Journal of Evolutionary Psychology, 5, 119-129.

Kendrick, K. M., Hinton, M. R., \& Atkins, K. (1998). Mothers determine male sexual preferences. Nature, 395, 229-230.

Krupp, D. B., DeBruine, L. M. \& Barclay, P. (2008). A cue of kinship promotes cooperation for the public good. Evolution and Human Behavior, 29, 49-55.

Little, A. C., DeBruine, L. M., \& Jones, B. C. (2005). Sexcontingent face after-effects suggest distinct neural populations code male and female faces. Proceedings of the Royal Society of London B, 272, 2283-2287.

Little, A. C., Penton-Voak, I. S., Burt, D. M., \& Perrett, D. I. (2003). Investigating an imprinting-like phenomenon in humans: Partners and opposite-sex parents have similar hair and eye colour. Evolution and Human Behavior, 24, 43-51.

Mateo, J. M. (2004). Recognition systems and biological organization: The perception component of social recognition. Annals Zoologica Fennici, 41, 729-745.

Mateo, J. M., \& Johnston, R. E. (2003). Kin recognition by self-referent phenotype matching: weighing the evidence. Animal Cognition, 6, 73-76.

Nesse, R. M., Silverman, A., \& Bortz, A. (1990). Sex differences in ability to recognize family resemblance. Ethol- ogy and Sociobiology, 11, 11-21.

Oda, R., Matsumoto-Oda, A., \& Kurashima, O. (2002). Facial resemblance of Japanese children to their parents. Journal of Ethology, 20, 81-85.

Parker, G., Tupling, H., and Brown, L. B. (1979) A Parental Bonding Instrument. British Journal of Medical Psychology, 52, 1-10.

Penton-Voak, I. S., Perrett, D. I., \& Peirce, J. W. (1999). Computer graphic studies of the role of facial similarity in judgments of attractiveness. Current Psychology, 18, 104117.

Perrett, D. I., Penton-Voak, I. S., Little, A. C., Tiddeman, B. P., Burt, D. M., Schmidt, N., et al. (2002). Facial attractiveness judgments reflect learning of parental age characteristics. Proceedings of the Royal Society of London B, 269, 873-880.

Platek, S. M., \& Kemp, S. M. (2009). Is family special to the brain? An event-related fMRI study of familiar, familial, and self-face recognition. Neuropsychologia, 47, 849-58.

Saxton, T. K., Little, A. C., Rowland, H. M., Gao, T., \& Roberts, S. C. (2009). Trade-offs between markers of absolute and relative quality in human facial preferences. Behavioral Ecology, 20, 1133-1137.

Wiszewska, A., Pawlowski, B., \& Boothroyd, L. G. (2007). Father-daughter relationship as a moderator of sexual imprinting: a facialmetric study. Evolution and Human Behavior, 28, 248 - 252. 